University of Nebraska - Lincoln

DigitalCommons@University of Nebraska - Lincoln

US Army Research

U.S. Department of Defense

2011

Detection of six serotypes of botulinum neurotoxin using fluorogenic reporters

\author{
Daniel R. Ruge \\ BioSentinel Pharmaceuticals \\ F. Mark Dunning \\ BioSentinel Pharmaceuticals \\ Timothy M. Piazza \\ University of Wisconsin-Madison \\ Brian E. Molles \\ US Army Medical Research Institute of Chemical Defense (USAMRICD) \\ Michael Adler \\ US Army Medical Research Institute of Chemical Defense (USAMRICD) \\ See next page for additional authors
}

Follow this and additional works at: https://digitalcommons.unl.edu/usarmyresearch

Part of the Operations Research, Systems Engineering and Industrial Engineering Commons

Ruge, Daniel R.; Dunning, F. Mark; Piazza, Timothy M.; Molles, Brian E.; Adler, Michael; Zeytin, Füsûn N.; and Tucker, Ward C., "Detection of six serotypes of botulinum neurotoxin using fluorogenic reporters" (2011). US Army Research. 149.

https://digitalcommons.unl.edu/usarmyresearch/149

This Article is brought to you for free and open access by the U.S. Department of Defense at DigitalCommons@University of Nebraska - Lincoln. It has been accepted for inclusion in US Army Research by an authorized administrator of DigitalCommons@University of Nebraska - Lincoln. 


\section{Authors}

Daniel R. Ruge, F. Mark Dunning, Timothy M. Piazza, Brian E. Molles, Michael Adler, Füsûn N. Zeytin, and Ward C. Tucker 


\title{
Detection of six serotypes of botulinum neurotoxin using fluorogenic reporters
}

\author{
Daniel R. Ruge ${ }^{a}$, F. Mark Dunning ${ }^{a}$, Timothy M. Piazza ${ }^{\mathrm{a}, \mathrm{b}}$, Brian E. Molles ${ }^{\mathrm{c}}$, Michael Adler ${ }^{\mathrm{c}}$, \\ Füsûn N. Zeytin ${ }^{a}$, Ward C. Tucker ${ }^{a, *}$ \\ ${ }^{a}$ BioSentinel Pharmaceuticals, Madison, WI 53719, USA \\ ${ }^{\mathrm{b}}$ Department of Forest and Wildlife Ecology, University of Wisconsin-Madison, Madison, WI 53706, USA

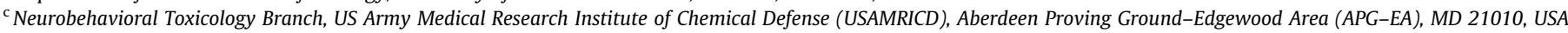

\section{A R T I C L E I N F O}

\section{Article history:}

Received 17 September 2010

Received in revised form 3 January 2011

Accepted 4 January 2011

Available online 7 January 2011

\section{Keywords:}

Botulinum neurotoxin

Proteases

FRET

High-throughput assays

\begin{abstract}
A B S T R A C T
Methods that do not require animal sacrifice to detect botulinum neurotoxins (BoNTs) are critical for BoNT antagonist discovery and the advancement of quantitative assays for biodefense and pharmaceutical applications. Here we describe the development and optimization of fluorogenic reporters that detect the proteolytic activity of BoNT/A, B, D, E, F, and G serotypes in real time with femtomolar to picomolar sensitivity. Notably, the reporters can detect femtomolar concentrations of BoNT/A in $4 \mathrm{~h}$ and BoNT/E in $20 \mathrm{~h}$, sensitivity that equals that of animal-based methods. The reporters can be used to determine the specific activity of BoNT preparations with intra- and inter-assay coefficients of variation of approximately $10 \%$. Finally, we find that the greater sensitivity of our reporters compared with those used in other commercially available assays makes the former attractive candidates for high-throughput screening of BoNT antagonists.
\end{abstract}

(c) 2011 Elsevier Inc. All rights reserved.
Botulinum neurotoxins (BoNTs), ${ }^{1}$ produced by the bacteria of the genus Clostridium, are the most lethal substances known. The zinc-dependent endopeptidases act by entering neurons and cleaving soluble $\mathrm{N}$-ethylmaleimide-sensitive factor attachment protein receptors (SNAREs) and, thus, compromise the protein machinery responsible for neurotransmitter release [1-8]. Failure to promptly treat a victim of BoNT poisoning can result in flaccid paralysis, respiratory failure, or death [9]. The combination of extreme potency and a lack of medical treatments other than antitoxin administration and intensive care has made BoNT a biodefense priority requiring the discovery and development of assays to quantify toxins and to identify antagonists to counteract intoxication [10-13].

Despite their lethality, BoNTs are widely used for cosmetic and pharmaceutical applications due in part to their exquisite specificity for the neuromuscular junction. BoNTs provide relief of muscle tension and pain by inhibiting neurons that cause excessive muscle contractions. Therapeutic preparations of BoNT/A and B serotypes are Food and Drug Administration (FDA) approved for treating

\footnotetext{
* Corresponding author. Fax: +1 6084418173.

E-mail address: wtucker@biosentinelpharma.com (W.C. Tucker).

1 Abbreviations used: BoNT, botulinum neurotoxin; SNARE, soluble $N$-ethylmaleimide-sensitive factor attachment protein receptor; MS, mass spectrometry; CFP, cyan fluorescent protein; YFP, yellow fluorescent protein; FRET, Förster resonance energy transfer; HTS, high-throughput screening; PCR, polymerase chain reaction; FP, fluorescent protein; LB, Luria-Bertani broth; PBS, phosphate-buffered saline; IPTG, isopropyl- $\beta$-D-thiogalactopyranoside; RT, room temperature; Ni-NTA, nickel-nitrilotriacetic acid; DTT, dithiothreitol; LOD, limit of detection; GFP, green fluorescent protein; SDS, sodium dodecyl sulfate; CV, coefficient of variation.
}

glabellar lines, strabismus, cervical dystonia, blepharospasm, cranial nerve VII disorders, and primary axillary hyperhidrosis. Dozens of "off-label" BoNT clinical applications have also been documented [14-17].

The mouse bioassay, or lethality test, has been the standard for testing BoNT-containing samples for the past 30 years [18-20]. Government agencies use this method for testing food and serum samples for the presence of BoNT, whereas the pharmaceutical industry uses it for quality control and to quantify "for human use" BoNT preparations. The test is carried out by injecting mice intraperitoneally with approximately $0.5 \mathrm{ml}$ of sample per mouse and recording the number of deaths over a 1- to 7-day period. The assay is very sensitive, with a detection limit of $5-10 \mathrm{pg}$ for BoNT/A [21,22]. Results for the mouse bioassay are reported in median lethal dose $\left(L_{50}\right)$ units, where $1 L^{2} D_{50}$ is the amount of BoNT required to kill $50 \%$ of injected mice after a defined time interval.

The mouse bioassay's low-throughput methodology limits its utility for BoNT antagonist development where small molecule library screening is impractical and could raise ethical concerns. Rapid and easily accessible assays that are not dependent on animal use are required to meet biodefense diagnostic and therapeutic needs. Furthermore, quality control profiles of BoNT-based drugs require reliable non-animal-based tests to measure drug-specific activity regardless of the manufacturer. Alternative methods that rely on immunology, liquid chromatography, mass spectrometry (MS), and fluorescence methods to detect BoNT proteolytic activity have emerged [23]. Notably, detection of multiple BoNT serotypes 
using a combination of immunological and MS methods has been reported with mouse bioassay sensitivity and utility in complex matrices such as serum and food products [24,25]. Drawbacks of both MS and liquid chromatography methods are their limited throughput and the requirement of expensive equipment. Fluorogenic methods offer a high-throughput alternative to either the mouse bioassay or immuno-MS methods. However, most fluorogenic assays use low-affinity substrates, are more than four orders of magnitude less sensitive than the mouse bioassay, and/or are limited to only a few BoNT serotypes [26-31].

Dong and coworkers described two recombinant reporters containing residues 141-206 and 33-94 of neuronal SNARE proteins SNAP-25 and synaptobrevin 2, respectively [32]. The substrates were expressed as fusions of cyan and yellow fluorescent proteins (CFP and YFP, respectively), enabling the detection of BoNT proteolytic activity by Förster resonance energy transfer (FRET). The fluorogenic reporters were found to be sensitive to BoNT/A, B, E, and $\mathrm{F}$ serotypes and able to detect picomolar concentrations of the toxins in real time.

Here we report advances in the development and optimization of FRET-based reporters that detect six of seven BoNT serotypes. Through changes in the expression, purification, and content of the reporters, we were able to generate FRET-based reporters with improved dynamic range and sensitivity. The resulting reporters are robust in terms of reagent and assay stability, and they provide sensitivity for BoNT not previously seen with fluorogenic substrates. The FRET-based reporters are suitable for high-throughput screening (HTS) for BoNT antagonists and for the development of sensitive, real-time, and quantitative BoNT detection methods that do not require animals.

\section{Materials and methods}

\section{Materials and reagents}

BoNT/A, B, D, and F serotypes, trypsin-treated BoNT/E, and trypsin-treated BoNT/G were provided by Metabiologics (Madison, WI, USA).

\section{Generation and expression of FRET-based reporters}

The constructs pTrcHisA-CFP-SNAP25 $5_{141-206}-$ YFP and pTrcHisA-CFP-Syb2 ${ }_{33-94}$-YFP were provided by E.R. Chapman (University of Wisconsin-Madison) [32]. The constructs were engineered to encode the 8-amino-acid StrepTagII sequence (WSHPQFEK) C terminal of the YFP moiety using standard polymerase chain reaction (PCR) techniques [33]. The resulting constructs, pTrcHisACFP-SNAP $141-206^{-Y F P-S t r e p T a g I I ~ a n d ~ p T r c H i s A-C F P-S y b 2 ~}{ }_{33-94^{-}}$ YFP-StrepTagII, were further modified to incorporate Venus mutations into YFP using standard site-directed mutagenesis and molecular biology techniques [34]. All resulting constructs encoded a protein with an N-terminal His6 tag, a C-terminal StrepTagII, a 4-amino-acid linker (GMAS) between the His6 tag and the donor fluorescent protein (FP), a 5-amino-acid linker (GGRSR) between the donor FP and the N terminus of SNAP25, a 6-amino-acid linker (SNSGGS) between the $C$ terminus of SNAP25 and the acceptor FP, and a 7-amino-acid linker (GIRSLAV) between the acceptor FP and the StrepTagII.

\section{Protein expression and purification}

All FRET reporter constructs were expressed in BL21 cells (Novagen) and purified by double affinity chromatography unless otherwise indicated. Luria-Bertani broth (LB, $50 \mathrm{ml}$ ) supplemented with $50 \mu \mathrm{g} / \mathrm{ml}$ carbenicillin was inoculated with a colony of BL21 cells transformed with the indicated construct and grown overnight at $37^{\circ} \mathrm{C}$ with shaking ( $250 \mathrm{rpm}$ ). Then $25 \mathrm{ml}$ of the overnight culture was transferred to $1 \mathrm{~L}$ of LB containing $50 \mu \mathrm{g} / \mathrm{ml}$ carbenicillin and grown to an $\mathrm{OD}_{600}$ of approximately 0.5 before induction of protein expression by the addition of $0.4 \mathrm{mM}$ isopropyl- $\beta$-D-thiogalactopyranoside (IPTG). The cultures were immediately transferred to $25{ }^{\circ} \mathrm{C}$ unless otherwise indicated (see Fig. 1A) and grown with shaking for an additional $7 \mathrm{~h}$. Cells were harvested by centrifugation $(8000 \mathrm{~g}, 10 \mathrm{~min})$, washed once with $30 \mathrm{ml}$ of phosphate-buffered saline (PBS), and frozen at $-80^{\circ} \mathrm{C}$.

Thawed cell pellets from 8-L cultures were resuspended with $240 \mathrm{ml}$ of B-Per Protein Extraction Reagent (Pierce) supplemented with $500 \mathrm{mM} \mathrm{NaCl}, 10 \mathrm{mM}$ imidazole ( $\mathrm{pH} \mathrm{8.0),} 6 \mathrm{kU}$ of benzonase (Novagen), $240 \mathrm{kU}$ of lysozyme (Novagen), and Complete Protease Inhibitor Cocktail (Roche). The cells were extracted for 20 min on a rotating platter at room temperature (RT) before centrifugation at $25,000 \mathrm{~g}$ for $20 \mathrm{~min}$. The supernatant was then incubated with $64 \mathrm{ml}$ of nickel-nitrilotriacetic acid (Ni-NTA)-Sepharose beads (50\% slurry, Qiagen) for $45 \mathrm{~min}$ with rotation at RT before centrifuging the beads at $500 \mathrm{~g}$ for $3 \mathrm{~min}$. The beads were washed three times with $30 \mathrm{ml}$ of wash buffer (50 mM Hepes-NaOH [pH 7.1], $500 \mathrm{mM} \mathrm{NaCl}$, and $10 \mathrm{mM}$ imidazole) and transferred to a $100-\mathrm{ml}$ column. The beads were washed with an additional 3 column volumes of wash buffer before elution of the protein in elution buffer (50 mM Hepes- $\mathrm{NaOH}$ [pH 7.1], $500 \mathrm{mM} \mathrm{NaCl}$, and $250 \mathrm{mM}$ imidazole) and the collection of 5-ml fractions.

Peak fractions were pooled and further purified by StrepTag affinity chromatography on a Bio-Rad BioLogic fast protein liquid chromatography (FPLC) system. His6-purified protein was injected onto three 5-ml StrepTrap HP columns (IBA) plumbed in tandem and equilibrated with 4 column volumes of wash buffer. Bound protein was then washed with 4 column volumes of wash buffer before eluting with 4-5 column volumes of $50 \mathrm{mM}$ Hepes- $\mathrm{NaOH}$ ( $\mathrm{pH} 8.0), 150 \mathrm{mM} \mathrm{NaCl}$, and $2.5 \mathrm{mM}$ D-desthiobiotin in $1-\mathrm{ml} \mathrm{fac}-$ tions. Peak fractions were pooled and dialyzed against $50 \mathrm{mM}$ Hepes- $\mathrm{NaOH}$ (pH 7.1), $10 \mathrm{mM} \mathrm{NaCl}$, and 15\% glycerol. The dialyzed reporters were quantified by bicinchoninic acid (BCA, Pierce), aliquoted, and stored at $-80^{\circ} \mathrm{C}$.

\section{Fluorescence measurements, BoNT assays, and analysis}

Fluorescence measurements were taken on a Varioskan spectral scanning multimode microplate reader (Thermo Scientific). Reporter titrations and BoNT activity experiments were carried out in $100 \mu \mathrm{l}$ of $50 \mathrm{mM}$ Hepes-NaOH (pH 7.1), $5 \mathrm{mM} \mathrm{NaCl}, 0.1 \%$ Tween $20,5 \mathrm{mM}$ dithiothreitol (DTT), and $10 \mu \mathrm{M} \mathrm{ZnCl}_{2}$ in black, flat-bottom, 96-well FluoroNunc plates (Nunc) unless otherwise indicated. The reporter concentrations were maintained at $250 \mathrm{nM}$ unless otherwise indicated.

Data analysis was carried out with Prism 4.0 software (GraphPad Software). For all line graphs, data shown are averages from triplicate determinations with bars indicating standard deviations. Raw spectral scanning data and electropherogram images are representative data from at least three experiments. Limits of detection (LODs) were calculated by determining the minimal BoNT concentration producing a signal more than 3 standard deviations below control values in the absence of BoNT $(n=6)$.

\section{Kinetics}

The Michaelis constant $\left(K_{\mathrm{M}}\right)$ and catalytic constant $\left(k_{\text {cat }}\right)$ were determined by titrating a fixed concentration of the indicated BoNT serotype ( $\leqslant 2 \mathrm{nM}$, reduced with $5 \mathrm{mM}$ DTT, $30 \mathrm{~min}$ ) with $0.2-$ $50 \mu \mathrm{M}$ of the indicated substrate (FRET reporter). Emission from 470 and $527 \mathrm{~nm}$ on $434 \mathrm{~nm}$ excitation was collected every 30$60 \mathrm{~s}$ for at least $20 \mathrm{~min}$. On completion of the kinetic reading, 
A

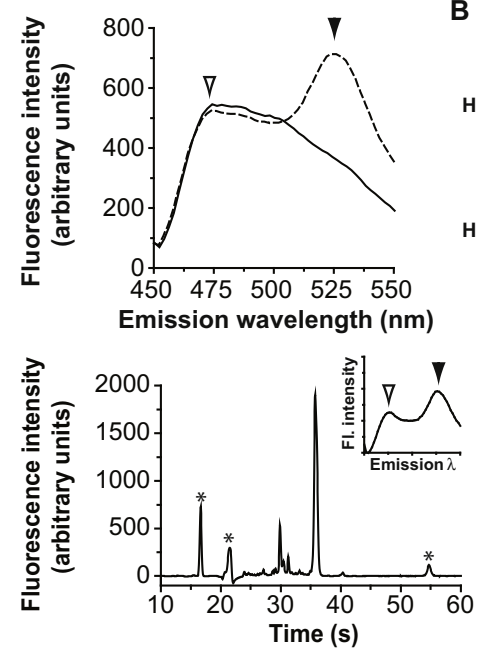

B
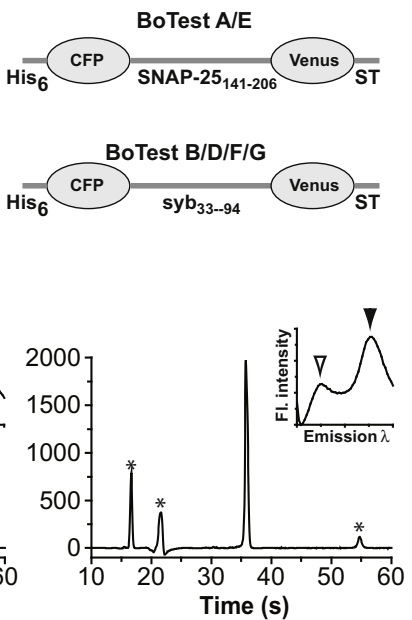

D

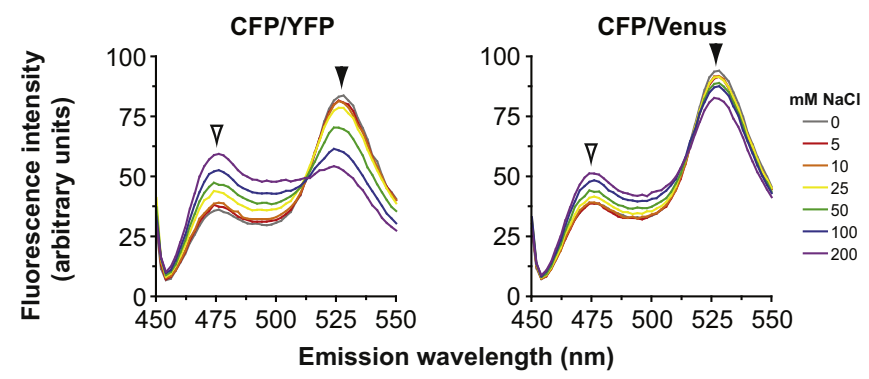

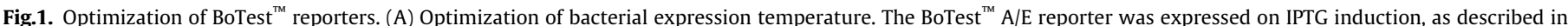

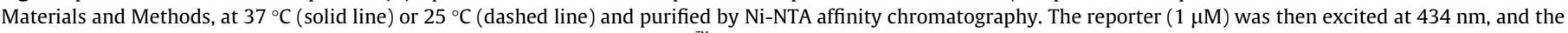

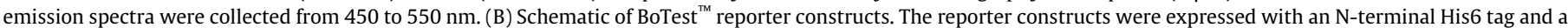

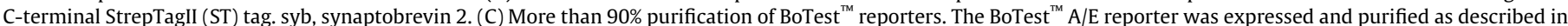

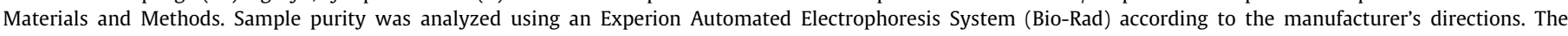

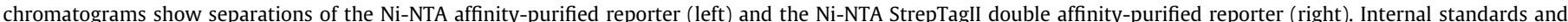

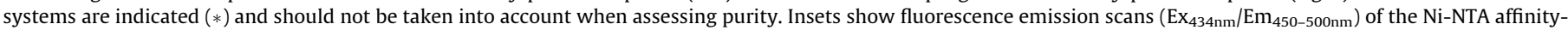

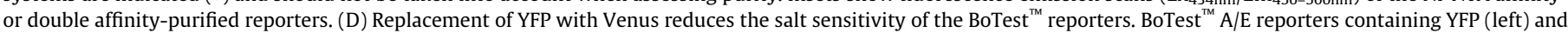

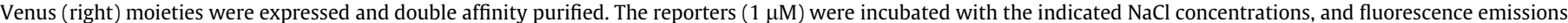
were collected as described in panel A. For all emission scans, the CFP and FRET peaks are denoted by open and closed arrowheads, respectively.

remaining substrate was allowed to digest overnight following the addition of excess BoNT ( $10 \mathrm{~nm}$, BoNTs/A and E) or $100 \mu \mathrm{g} / \mathrm{ml}$ trypsin for $30 \mathrm{~min}$ (BoNTs/B, D, and F). Emission spectra were determined from the completely digested substrate.

Substrate disappearance was calculated at each time point and for a particular substrate concentration using the equation $(X-$ neg)/(pos - neg), where $X$ is the emission value (527/470) at a given time point, neg is the value in the absence of BoNT, and pos is the value on the complete conversion of substrate into product. Substrate disappearance at each substrate concentration was plotted as a function of time, and the linear range of substrate disappearance $(<20 \%$ conversion) was fitted by linear regression. The slopes of the line or velocities $(v)$ were then plotted as a function of substrate concentration $([S])$, and the data were fitted by the Michaelis-Menten equation, $v=\left(V_{\max } *[S]\right) /\left(K_{\mathrm{m}}+[S]\right)$, using Prism software.

\section{Results}

\section{Expression and purification of FRET reporters}

The recombinant FRET reporters described by Dong and coworkers are composed of CFP and YFP connected by linkers containing residues 141-206 of SNAP-25 and 33-94 of synaptobrevin 2 [32]. The recombinant reporters have been named BoTest ${ }^{\mathrm{TM}}$ along with the designation of A/E (BoTest ${ }^{\mathrm{TM}} \mathrm{A} / \mathrm{E}$, CFP-SNAP-25 ${ }_{141-206^{-}}$ YFP) or B/D/F/G (BoTest ${ }^{\mathrm{TM}} \mathrm{B} / \mathrm{D} / \mathrm{F} / \mathrm{G}, \mathrm{CFP}-$ Synaptobrevin2 $33-94-\mathrm{YFP}$ ) based on the specificity of their respective substrates for the different BoNT serotypes as described below. The CFP and YFP moieties form a FRET pair where, in the intact reporter, CFP excitation leads to YFP excitation by FRET, thereby quenching the fluorescence emission from CFP while increasing the fluorescence emission from YFP. Treating the reporter with BoNT leads to linker cleavage and loss of FRET, thereby decreasing YFP emission and increasing CFP emission. Cleavage of the reporters can be followed in real time by measuring the ratio of YFP to CFP emission.

On initial characterization, we found that the BoTest ${ }^{\mathrm{TM}}$ reporters as previously described suffered from low yields and low purity on expression and purification. In addition, the dynamic range of the assay was limited by small changes in FRET fluorescence on cleavage of the reporters by BoNT [32]. We addressed these problems by examining the bacterial expression conditions for producing the reporters and modifying the constructs to include alternative fluorophores and additional affinity purification tags (Fig. 1). Reducing the reporter bacterial expression temperature to $25^{\circ} \mathrm{C}$ from $37^{\circ} \mathrm{C}$ resulted in a dramatic increase in FRET fluorescence as judged by an increase in fluorescence emission at $526 \mathrm{~nm}$, the fluorescence emission maximum for YFP (Fig. 1A). In addition, the drop in expression temperature improved lot-to-lot reporter consistency (data not shown). The increased FRET fluorescence on reducing the expression temperature likely reflects the poor folding and 
maturation characteristics of YFP at $37^{\circ} \mathrm{C}$ [34]. Thus, the lowered expression temperatures increased the proportion of reporter molecules that have functional fluorescent proteins.

The full-length BoTest ${ }^{\mathrm{TM}}$ reporters copurified with lower molecular weight proteins on subjecting the protein extracts to Ni-NTA affinity chromatography, limiting the purity of the reporters to $60-70 \%$ (Fig. 1C). In an effort to eliminate these low-molecularweight proteins, we tested increasing the stringency of the affinity purification, alternative bacterial expression cell lines, and a C-terminal His-tag version of the reporter, all to no avail (data not shown). Therefore, we incorporated a second affinity tag to allow double affinity purification of the reporters, adding a StrepTagII affinity tag to the $C$ terminus of the reporter (Fig. 1B) [33]. The reporters were first purified by Ni-NTA affinity chromatography via the N-terminal His6 tag and then subjected to StrepTactin affinity chromatography, yielding high-purity BoTest $^{\mathrm{TM}}$ reporters (Fig. 1C). The BoTest ${ }^{\mathrm{TM}} \mathrm{A} / \mathrm{E}$ and BoTest ${ }^{\mathrm{TM}} \mathrm{B} / \mathrm{D} / \mathrm{F} / \mathrm{G}$ reporters are now routinely purified to greater than $90 \%$ homogeneity. The double affinity purification scheme also increased the ratio of FRET fluorescence to CFP fluorescence, indicating that some of the lower molecular weight proteins were composed of truncated products containing fluorescent CFP but no or truncated YFP (Fig. 1C, insets).

The final change to the reporters was the replacement of YFP with the YFP derivative Venus. Venus differs from YFP by 5 amino acid mutations that improve protein folding characteristics and reduce fluorescence quenching by halide anions [34]. We found that replacement of YFP with Venus reduced the reporter's $\mathrm{NaCl}$ sensitivity, increasing the FRET emission of the reporters in the presence of salt-containing buffers (Fig. 1D). The cumulative effects of the expression, purification, and fluorophore changes resulted in high-purity reporters with greatly improved FRET emission compared with the original reporters.

\section{Reporter fluorescence performance, signal linearity, and stability}

The improved fluorescence properties of the reporters increased assay dynamic range. BoNT proteolytic activity produced a dramatic decrease in FRET fluorescence emission and a concurrent increase in CFP emission (Fig. 2A). The ratio of FRET fluorescence to CFP fluorescence dropped from approximately 2.5 in the absence of BoNT to 0.6 in the presence of BoNT/A for the BoTest ${ }^{\mathrm{TM}} \mathrm{A} / \mathrm{E}$ reporter. For the BoTest ${ }^{\mathrm{TM}} \mathrm{B} / \mathrm{D} / \mathrm{F} / \mathrm{G}$ reporter, the ratio dropped from approximately 3.6 in the absence of BoNT to 0.6 in the presence of BoNT/B. The previous iteration of the reporters had a ratiometric (FRET emission/CFP emission) value of approximately 0.75 in the absence of BoNT and 0.55 in the presence of BoNT [32]. Thus, assay dynamic range was improved approximately 10 - to 15 -fold on implementation of the changes described above.

BoNT reporters containing a single CFP moiety and single or multiple YFP moieties were previously shown to exhibit nonlinear fluorescence emission characteristics on reporter dilution [29]. The ratio of FRET fluorescence emission to CFP fluorescence increased with increasing reporter concentrations, indicating that FRET efficiency was concentration dependent. This effect may be due to reporter dimerization at high nanomolar to micromolar concentrations where intermolecular FRET, in addition to concentrationindependent intramolecular FRET, contributes to the overall FRET fluorescence emission. Indeed, some green fluorescent protein (GFP) derivatives exhibit concentration-dependent dimerization $[35,36]$. These nonlinear effects have consequences for assay precision because errors in reporter dilution can lead to changes in the ratiometric value of the assay, thereby reducing accuracy. In addition, the change in ratiometric value in response to BoNT cleavage or the interactions between BoNT and the reporter substrate may be influenced by intermolecular reporter dimerization. Therefore, we tested whether the BoTest ${ }^{\mathrm{TM}}$ reporters exhibited nonlinear concentration-dependent changes in fluorescence emission.

We found that both the FRET and CFP fluorescence emissions increased in a linear fashion with increased BoTest ${ }^{\mathrm{TM}} \mathrm{A} / \mathrm{E}$ reporter concentrations of up to $8 \mu \mathrm{M}$ (Fig. 2B). The linear increases were independent of whether or not the reporter was cleaved with BoNT. Between 8 and $16 \mu \mathrm{M}$, there was a small nonlinearity in both FRET and CFP emissions, likely due to inner filter effects; no evidence of intermolecular FRET was seen [37]. Finally, reporter
A

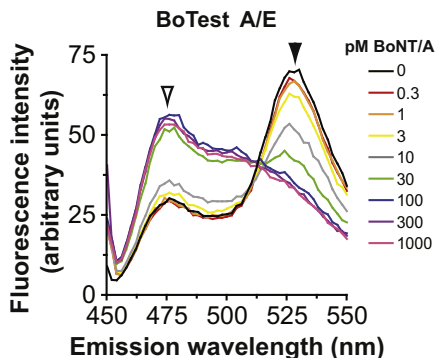

B

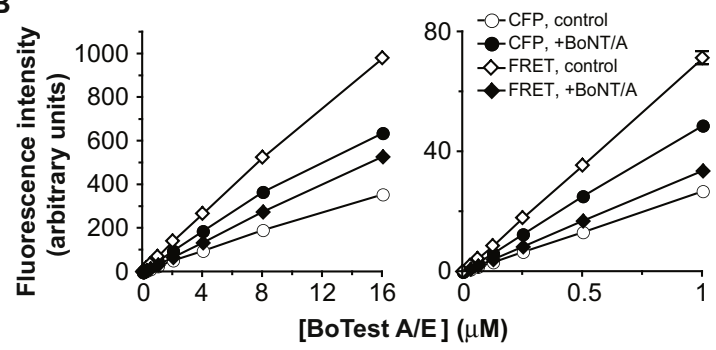

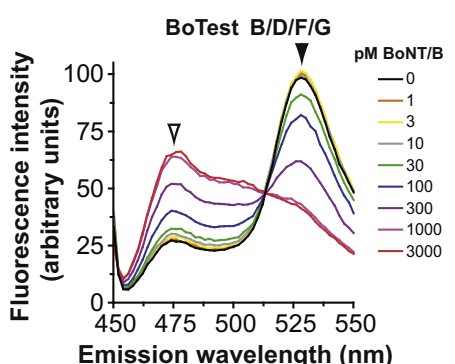

$c$

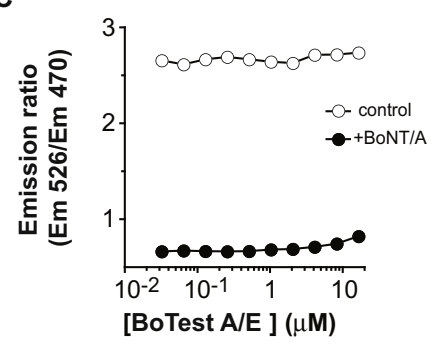

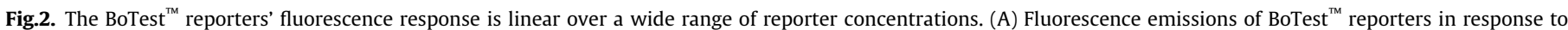

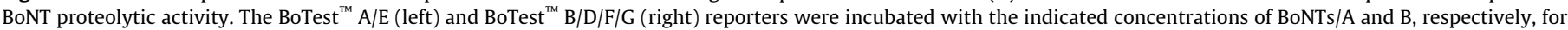

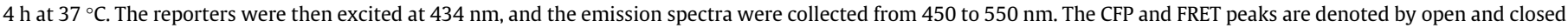

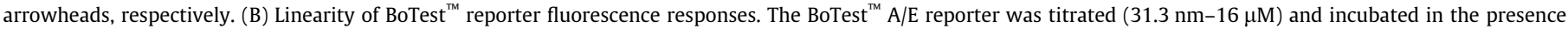

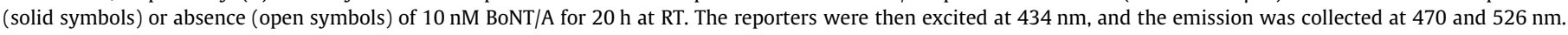

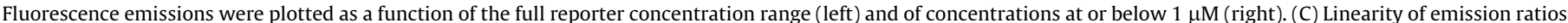

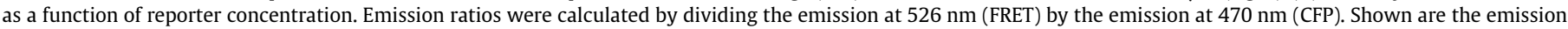
ratios in the presence and absence of $10 \mathrm{~nm}$ BoNT/A. 
ratiometric values were concentration independent in the presence and absence of BoNT, indicating that FRET efficiency is solely dependent on the intramolecular interactions of the CFP and YFP moieties (Fig. 2C). These data indicate that reporter fluorescence performance will not be subject to errors in reporter dilution. Similar results were seen with the BoTest ${ }^{\mathrm{TM}} \mathrm{B} / \mathrm{D} / \mathrm{F} / \mathrm{G}$ reporter (data not shown).

The stability of BoTest ${ }^{\mathrm{TM}}$ reporters' fluorescence characteristics and BoNT sensitivity was examined in response to prolonged storage at elevated temperatures and to freeze-thaw cycling (see Supplementary material). The reporters were found to be stable on storage at RT (or $37^{\circ} \mathrm{C}$ ) for up to 7 days, as indicated by an absence of loss in fluorescence emission or BoNT sensitivity (see Suppl. Fig. 1 in supplementary material). In addition, the reporters could be freeze-thawed 10 times without loss in performance (Suppl. Fig. 2). The data indicate that reporter CFP and Venus moieties do not denature under the conditions examined and that the reporters are stable and robust.

\section{Sensitivity of BoTest ${ }^{\mathrm{TM}}$ reporters, time, and temperature dependence}

The BoTest ${ }^{\mathrm{TM}} \mathrm{A} / \mathrm{E}$ reporter has the potential to detect the proteolytic activity of BoNTs/A, C, and E, whereas the BoTest ${ }^{\mathrm{TM}} \mathrm{B} / \mathrm{D} / \mathrm{F} / \mathrm{G}$ reporter has the potential to detect the proteolytic activity of BoN$\mathrm{Ts} / \mathrm{B}, \mathrm{D}, \mathrm{F}$, and $\mathrm{G}$. We found that the BoTest ${ }^{\mathrm{TM}} \mathrm{A} / \mathrm{E}$ reporter was sensitive to BoNT/A holotoxin and trypsinized (nicked) BoNT/E (BoNT/ $E_{\text {tryp }}$ ) holotoxin with detection of less than $10 \mathrm{pM}$ of each toxin possible within $1 \mathrm{~h}$ (Fig. 3). The sensitivity of the BoTest ${ }^{\mathrm{TM}} \mathrm{A} / \mathrm{E}$ reporter to BoNT/A was both time and temperature dependent (Fig. 3, upper panels). At $37^{\circ} \mathrm{C}$, the reaction was largely complete after $1 \mathrm{~h}$, with very little additional cleavage seen even after $4 \mathrm{~h}$. At 25 or $30^{\circ} \mathrm{C}$, BoNT/A continued to cleave reporter for up to $20 \mathrm{~h}$, with $300 \mathrm{fM}$ toxin being detectable at both temperatures. The temperature dependency of BoNT/A cleavage of the BoTest ${ }^{\mathrm{TM}}$ $\mathrm{A} / \mathrm{E}$ reporter likely reflects the thermal stability of BoNT/A rather than the stability of the reporter given that incubation of the reporter at $37^{\circ} \mathrm{C}$ for up to 7 days does not affect the sensitivity of the reporter to BoNT/A (Suppl. Fig. 1). BoTest ${ }^{\mathrm{TM}} \mathrm{A} / \mathrm{E}$ reporter sensitivity to BoNT/ $E_{\text {tryp }}$ was time dependent but unaffected by temperature variation between 25 and $37^{\circ} \mathrm{C}$ (Fig. 3, lower panels). BoNT/E continued to cleave the reporter for up to $20 \mathrm{~h}$ at all temperatures tested. BoNT/C holotoxin (up to $10 \mathrm{~nm}$ ) did not cleave the BoTest ${ }^{\mathrm{TM}}$ $\mathrm{A} / \mathrm{E}$ reporter (data not shown).

The BoTest ${ }^{\mathrm{TM}} \mathrm{B} / \mathrm{D} / \mathrm{F} / \mathrm{G}$ reporter detected the proteolytic activity of BoNT/B, D, and F holotoxin and trypsin-treated BoNT/G with varying sensitivities (Fig. 4). Picomolar quantities of BoNTs/B, D, and $\mathrm{F}$ were detectable within $1-2 \mathrm{~h}$ of incubation at $37^{\circ} \mathrm{C}$, whereas detection of picomolar quantities of BoNT/G required overnight incubation.

Table 1 summarizes the LODs for the six detectable serotypes of BoNT. Less than $30 \mathrm{pM}$ of the six serotypes could be detected within a 20-h incubation, although the LODs varied considerably among the serotypes. In addition, we found that LODs were dependent on the lot of BoNTs tested and the degree of "nicking" that the BoNTs undergo during expression. For example, the LODs for two lots of BoNT/A varied 3- to 10-fold depending on the incubation temperature and time (Table 1 ). In addition, detection of BoNT/B could be enhanced 3-fold by trypsin treatment of the toxin. Exogenous proteolytic nicking of certain clostridial toxins, notably serotypes B, D, $\mathrm{E}$, and $\mathrm{F}$, is required to generate the fully active dichain form of BoNT given that these toxins are only partially activated by endogenous proteases during bacterial expression [38-40]. These data indicate that the BoTest ${ }^{\mathrm{TM}}$ LODs will be greatly affected by the "nicked" status of the BoNT preparations.

One mouse $\mathrm{LD}_{50}$ is estimated to be $4-20 \mathrm{pg}$ of BoNT per injection depending on the serotype under consideration and the toxicity of the particular preparation of BoNT [21,22]. BoNTs/A and E ( $300 \mathrm{fM}$ ) could be detected under optimal conditions, corresponding to approximately $4.5 \mathrm{pg}$ of BoNT in the $100-\mu$ reaction volume. Thus, the mouse bioassay level of detection of BoNTs/A and $E$ is possible with the BoTest ${ }^{\mathrm{TM}} \mathrm{A} / \mathrm{E}$ reporter. BoNTs/B $\mathrm{B}_{\text {tryp }}$ and $\mathrm{F}$ ( $3 \mathrm{pM}$ or $\sim 45 \mathrm{pg}$ ) were detectable on extended 20 -h incubations with the BoTest ${ }^{\mathrm{TM}} \mathrm{B} / \mathrm{D} / \mathrm{F} / \mathrm{G}$ reporter, whereas more than $30 \mathrm{pM}$ or $450 \mathrm{pg}$ of BoNTs/D and $\mathrm{G}$ was detectable. Thus, the BoTest ${ }^{\mathrm{TM}}$ reporters are able to detect two serotypes ( $A$ and $E$ ) with mouse bioassay sensitivity, two serotypes ( $B$ and $F$ ) within an order of magnitude of bioassay sensitivity, and two serotypes (D and $G$ ) within two orders of magnitude of bioassay sensitivity.
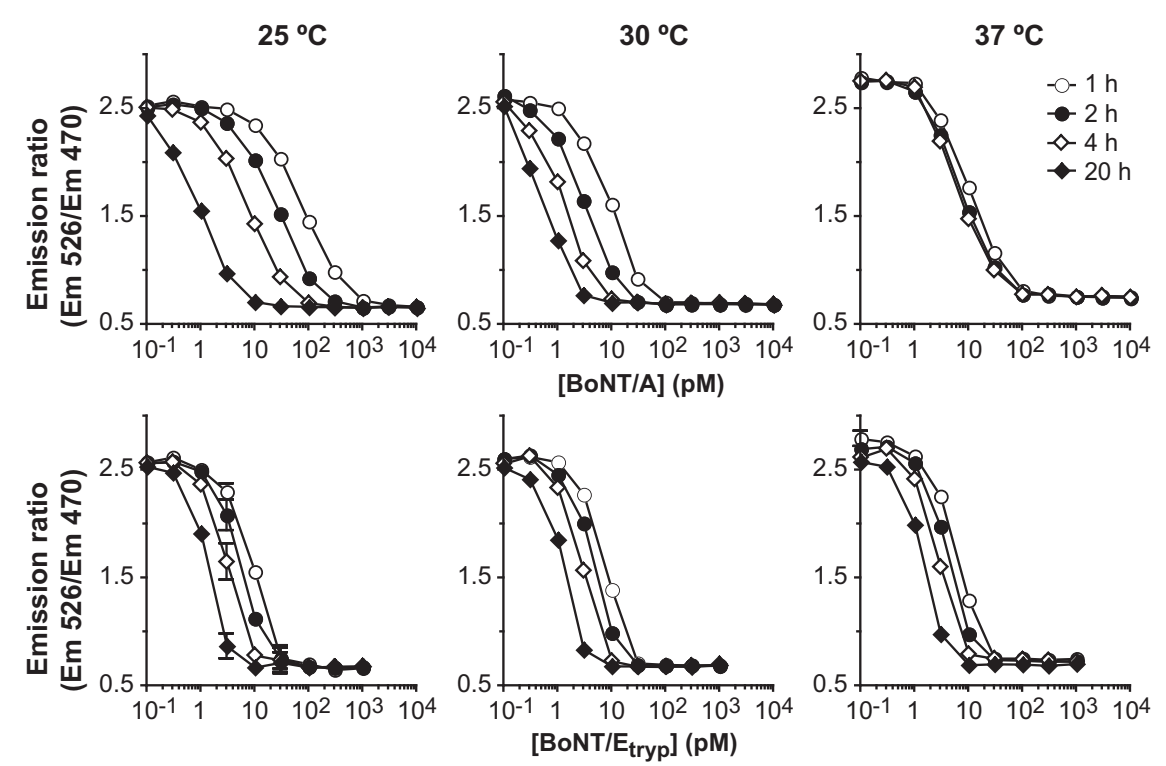

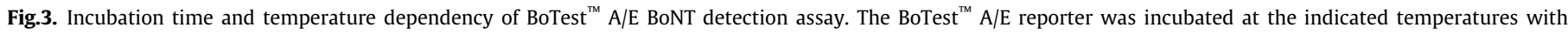

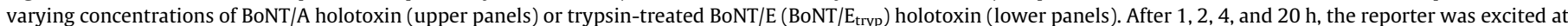

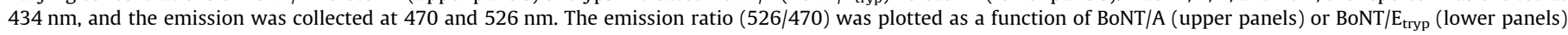
concentration. 

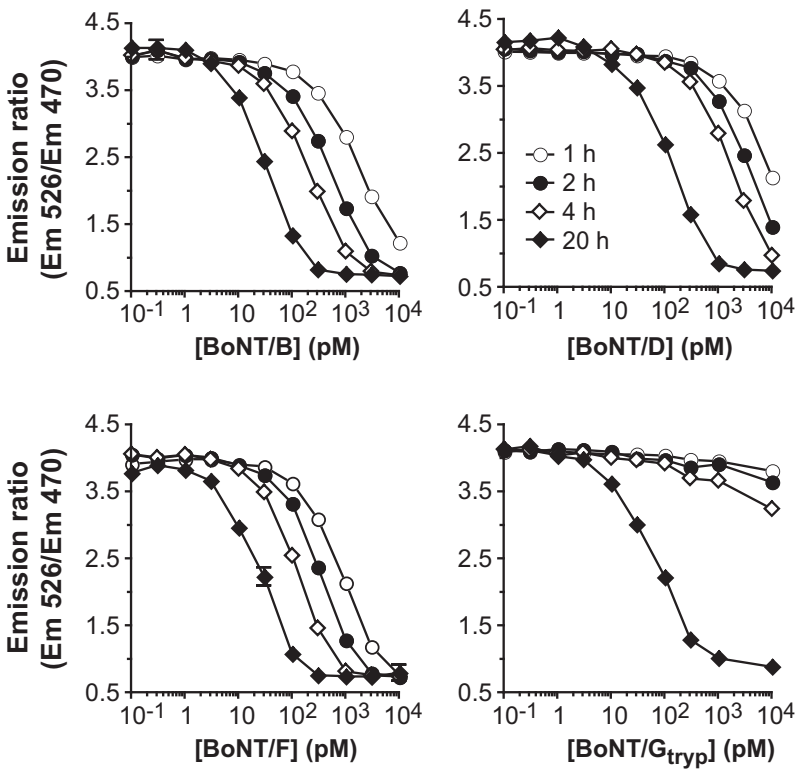

Fig.4. Incubation time dependency of BoTest ${ }^{\mathrm{TM}} \mathrm{B} / \mathrm{D} / \mathrm{F} / \mathrm{G}$ BoNT detection assay. The BoTest $^{\mathrm{TM}} \mathrm{B} / \mathrm{D} / \mathrm{F} / \mathrm{G}$ reporter was incubated with varying concentrations of BoNT/B, trypsin-treated BoNT/G (BoNT/G $/ G_{\text {tryp }}$ ), BoNT/D, or BoNT/F holotoxin. After 1, 2, 4, and $20 \mathrm{~h}$, the reporter was excited at $434 \mathrm{~nm}$, and the emission was collected at 470 and $526 \mathrm{~nm}$. The emission ratio (526/470) was plotted as a function of BoNT concentration.

\section{Real-time detection of substrate disappearance}

A potential advantage of using a ratiometric fluorescence readout to detect BoNT-dependent BoTest ${ }^{\mathrm{TM}}$ reporter cleavage is the ability to directly correlate changes in the ratiometric value to changes in substrate (intact reporter) concentration. Therefore, we tested whether changes in the ratiometric fluorescence value on the addition of increasing BoNT/A concentrations yielded corresponding and proportional changes in intact BoTest ${ }^{\mathrm{TM}}$ reporter (substrate) concentrations (Fig. 5). The BoTest ${ }^{\mathrm{TM}} \mathrm{A} / \mathrm{E}$ reporter was titrated with BoNT/A, and the ratiometric value was determined (Fig. 5A) immediately before adding sodium dodecyl sulfate (SDS) buffer and analyzing the reaction for the presence of intact BoTest $^{\mathrm{TM}}$ reporter and cleavage products by automated electrophoresis (Fig. 5B). Intact reporter was clearly resolved from cleavage products in electropherograms. Overlaying normalized ratiometric values with the percentage intact reporter as a function of BoNT/A concentration indicated that changes in the ratiometric fluorescence values were closely correlated with remaining intact reporter concentration (Fig. 5C). Finally, the normalized ratiometric values from three independent runs were plotted against the amounts of intact reporter remaining from the runs as determined by automated electrophoresis (Fig. 5D). The data fit demonstrates that the ratiometric value is highly dependent on the amount of remaining intact BoTest $^{\mathrm{TM}}$ reporter, with a slope approaching unity $\left(0.97 \pm 0.02, r^{2}=0.99\right)$. Thus, substrate concentration can be followed in real time so long as the starting ratiometric value before the addition of BoNT and the saturated ratiometric value in the presence of excess BoNT are known.

The ability to easily determine the BoTest ${ }^{\mathrm{TM}}$ reporter (substrate) concentration in real time allows the rapid and potentially accurate assessment of specific enzymatic activity from a given BoNT preparation. We titrated the BoTest ${ }^{\mathrm{TM}} \mathrm{A} / \mathrm{E}$ reporter with BoNT/A and measured the ratiometric fluorescence value of the reporter every $30 \mathrm{~s}$ to determined the BoNT/A preparation's specific activity (Fig. 6). The raw ratiometric fluorescence values were normalized and converted to substrate concentration (Fig. 6A). The initial velocity of reaction at varying BoNT/A concentrations was then determined by linear regression of the data points between 1 and $10 \mathrm{~min}$ (Fig. 6B). The initial velocity was then plotted as a function of BoNT/A concentration (Fig. 6C). The linear range of the plot was fitted again by regression, and specific activity was determined (in nM substrate cleaved $\min ^{-1} \mathrm{nM}$ BoNT/ $/ \mathrm{A}^{-1}$ ). Finally, the BoNT/A preparation's specific activity was determined independently in three successive runs, with each experiment using independently diluted BoNT/A and reagents (Fig. 6D). The data show that a BoNT/A preparation's specific activity can be determined with an intraassay coefficient of variation (CV) of $9.0-10.5 \%$ and an interassay CV of 9.5\%. This is considerably more accurate than the mouse bioassay, where CVs are typically on the order of 20$40 \%$ depending on the methods and the number of mice used, with the more accurate bioassay methods requiring more than 100 mice for a single determination $[20,41]$.

\section{BoTest $^{\mathrm{TM}}$ kinetic parameters}

We determined the relative affinities and catalytic efficiencies of BoTest ${ }^{\mathrm{TM}}$ reporter cleavage by BoNT (Table 2). The Michaelis constant $\left(K_{\mathrm{M}}\right)$ values for BoTest ${ }^{\mathrm{TM}} \mathrm{A} / \mathrm{E}$ cleavage by BoNT/A and $\mathrm{E}$ holotoxin were determined to be less than $1 \mu \mathrm{M}$, likely reflecting the extensive BoNT/A and E binding elements contained within the reporter $[6,42]$. Comparisons between kinetic parameters determined by multiple laboratories are difficult due to difference

Table 1

Limits of detection for the BoTest ${ }^{\mathrm{TM}}$ reporters.

\begin{tabular}{|c|c|c|c|c|c|c|c|c|c|}
\hline \multirow[t]{3}{*}{ Temperature $\left({ }^{\circ} \mathrm{C}\right)$} & \multirow[t]{3}{*}{ Time $(\mathrm{h})$} & \multicolumn{3}{|c|}{ BoTest $^{\mathrm{TM}} \mathrm{A} / \mathrm{E}$} & \multicolumn{5}{|c|}{ BoTest $^{\mathrm{TM}} \mathrm{B} / \mathrm{D} / \mathrm{F} / \mathrm{G}$} \\
\hline & & \multicolumn{2}{|c|}{ BoNT/A } & \multirow{2}{*}{ BoNT/E $\mathrm{E}_{\text {tryp }}$} & \multirow[t]{2}{*}{ BoNT/B } & \multirow{2}{*}{ BoNT/B $B_{\text {tryp }}$} & \multirow[t]{2}{*}{ BoNT/D } & \multirow[t]{2}{*}{ BoNT/F } & \multirow{2}{*}{ BoNT/G $/ G_{\text {tryp }}$} \\
\hline & & lot 1 & lot 2 & & & & & & \\
\hline \multirow[t]{4}{*}{25} & 1 & 10 & 30 & 3 & 1000 & 100 & 1000 & 100 & $>10000$ \\
\hline & 2 & 3 & 10 & 3 & 100 & 100 & 1000 & 100 & 10000 \\
\hline & 4 & 3 & 3 & 1 & 100 & 30 & 300 & 30 & 1000 \\
\hline & 20 & 0.3 & 0.3 & 1 & 10 & 3 & 100 & 3 & 30 \\
\hline \multirow[t]{4}{*}{30} & 1 & 3 & 10 & 3 & 100 & 100 & 1000 & 100 & $>10000$ \\
\hline & 2 & 1 & 10 & 3 & 30 & 10 & 300 & 100 & 300 \\
\hline & 4 & 0.3 & 3 & 1 & 30 & 10 & 300 & 30 & 300 \\
\hline & 20 & 0.3 & 0.3 & 0.3 & 10 & 3 & 100 & 3 & 30 \\
\hline \multirow[t]{4}{*}{37} & 1 & 3 & 10 & 3 & 100 & 30 & 1000 & 100 & $>10000$ \\
\hline & 2 & 3 & 10 & 3 & 30 & 10 & 300 & 30 & 300 \\
\hline & 4 & 3 & 10 & 1 & 30 & 10 & 300 & 30 & 300 \\
\hline & 20 & ND & 3 & 1 & 10 & 3 & 30 & 10 & 30 \\
\hline
\end{tabular}

Note: Values are in picomolars (pM) BoNT. ND, not determined. 
A
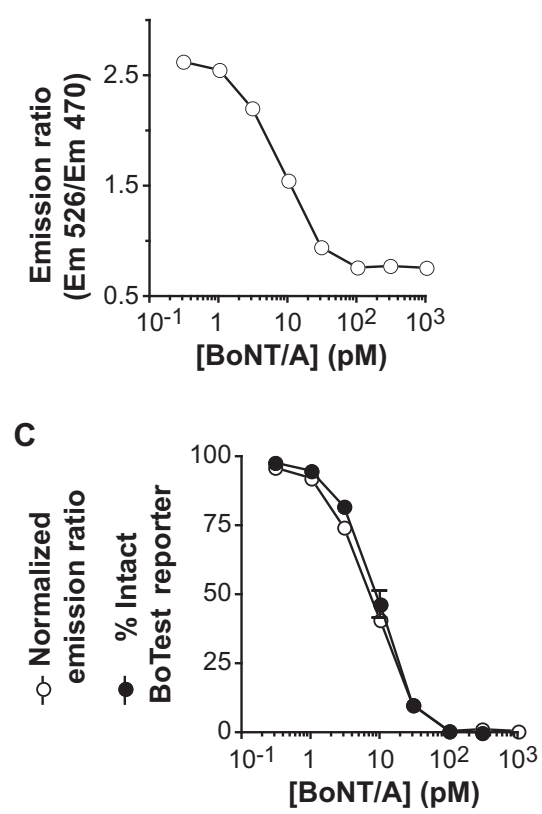

B

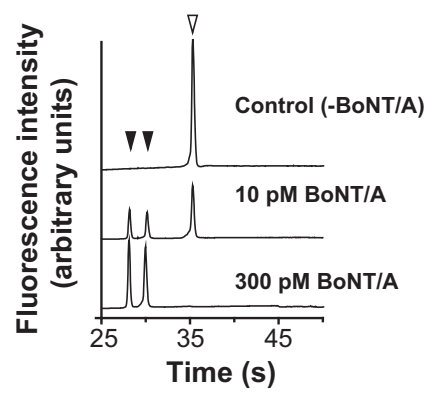

D

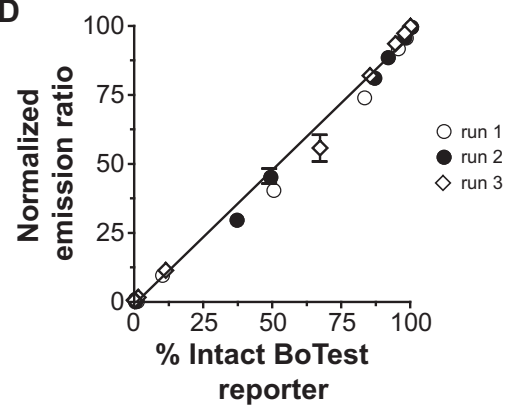

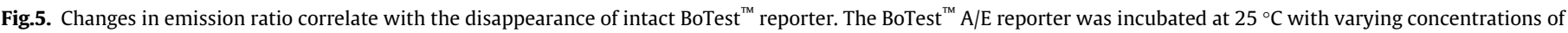

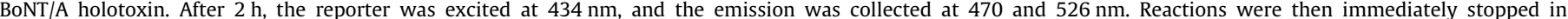

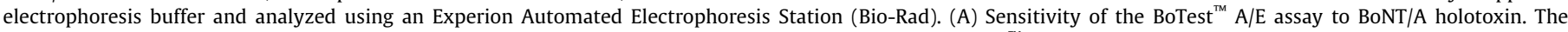

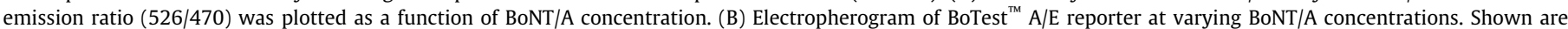

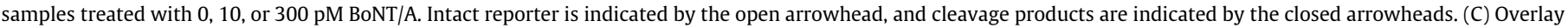

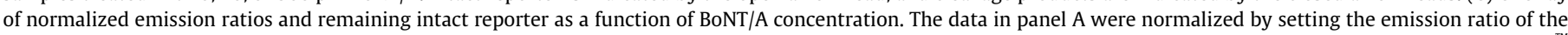

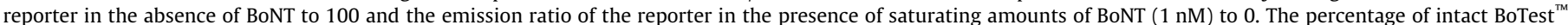

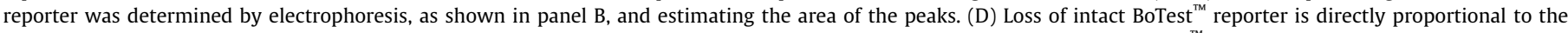

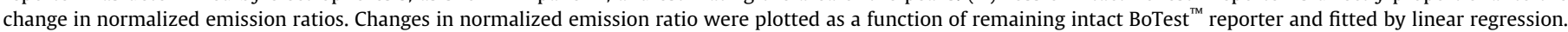
Data are from three independent runs.

A

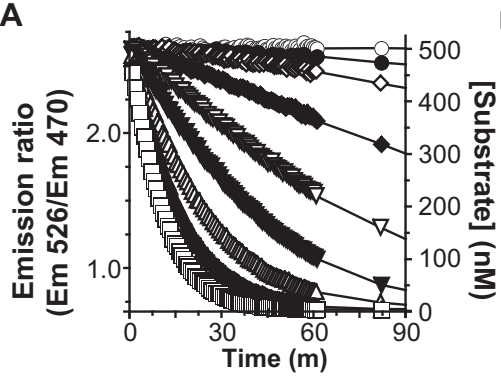

C

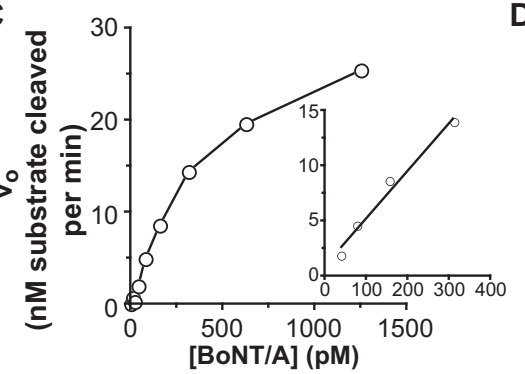

[BoNT/A] (pM)$$
\rightarrow-0
$$$$
\rightarrow-9.8
$$

$\sim 19.5$

$\rightarrow-39.6$

$\rightarrow-78.1$

$\rightarrow-156$

$-\Delta-313$

$\pm 625$

$-\square-1250$
B

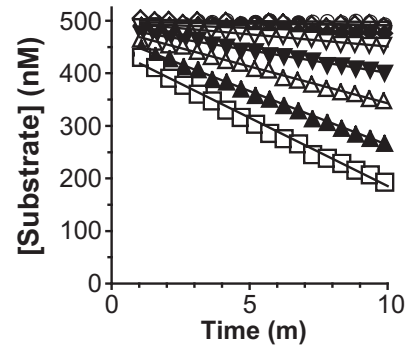

\begin{tabular}{cccc}
\hline $\begin{array}{c}\text { Specific activity } \\
\text { Run (nM substrate cleaved } \\
\text { per min per nM BoNT/A) }\end{array}$ & $\begin{array}{c}\text { Intraassay } \\
\text { CV (\%) }\end{array}$ & $\begin{array}{c}\text { Interassay } \\
\text { CV (\%) }\end{array}$ \\
\hline 1 & $43.07+/-4.52$ & 10.5 & \\
2 & $43.94+/-4.04$ & 9.2 & 9.5 \\
3 & $47.03+/-4.22$ & 9.0 & \\
\hline
\end{tabular}

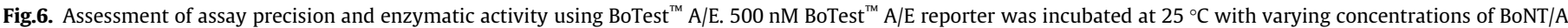

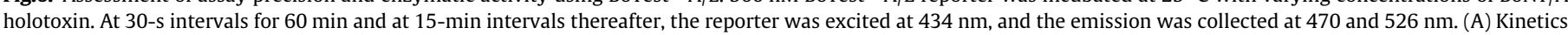

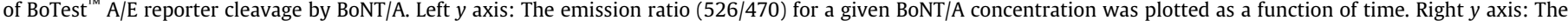

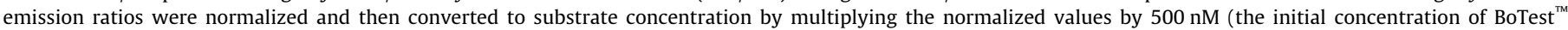

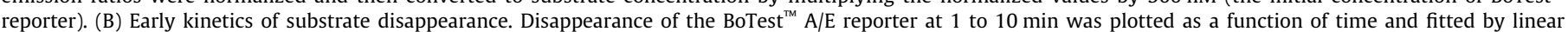

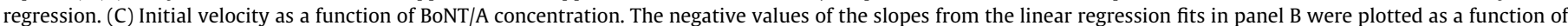

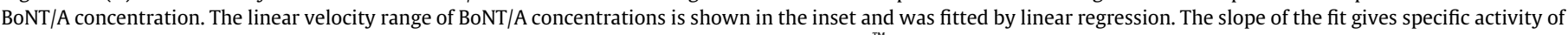

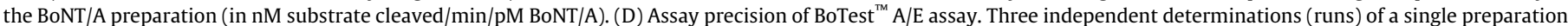

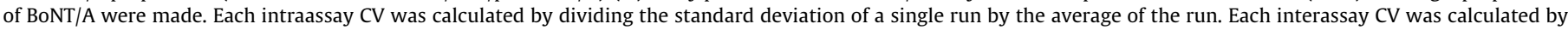
dividing the standard deviation of the three runs by the average of the three runs. 
Table 2

Kinetic constants of BoTest ${ }^{\mathrm{TM}}$ reporter cleavage by BoNT.

\begin{tabular}{|c|c|c|c|c|c|}
\hline & \multicolumn{2}{|l|}{ BoTest $^{\mathrm{TM}} \mathrm{A} / \mathrm{E}$} & \multicolumn{3}{|c|}{ BoTest $^{\mathrm{TM}} \mathrm{B} / \mathrm{D} / \mathrm{F} / \mathrm{G}$} \\
\hline & BoNT/A & BoNT/E $/ E_{\text {tryp }}$ & BoNT/B & BoNT/D & BoNT/F \\
\hline$K_{\mathrm{M}}(\mu \mathrm{M})$ & $0.67 \pm 0.06$ & $0.45 \pm 0.16$ & $15.9 \pm 2.4$ & $17.5 \pm 2.0$ & $8.50 \pm 1.7$ \\
\hline $\mathrm{k}_{\text {Cat }}\left(\mathrm{s}^{-1}\right)$ & $4.16 \pm 0.28$ & $14.6 \pm 1.1$ & $1.43 \pm 0.72$ & $0.30 \pm 0.02$ & $4.38 \pm 0.53$ \\
\hline $\mathrm{k}_{\text {Cat }} / K_{\mathrm{M}}\left(\mu \mathrm{M}^{-1} \mathrm{~s}^{-1}\right)$ & $6.18 \pm 0.20$ & $36.3 \pm 16$ & $0.11 \pm 0.05$ & $0.017 \pm 0.002$ & $0.58 \pm 0.9$ \\
\hline
\end{tabular}

in the substrates, BoNT forms (e.g., light chain vs. holotoxin), assays, and reaction conditions used. However, the $K_{\mathrm{M}}$ values for recombinant light chain cleavage of recombinant SNAP-25 were previously determined to be $10-41 \mu \mathrm{M}$ and $5-8 \mu \mathrm{M}$ for BoNTs/A and E, respectively [43-46]. The $K_{\mathrm{M}}$ values determined for cleavage of BoTest ${ }^{\mathrm{TM}} \mathrm{A} / \mathrm{E}$ are one order of magnitude lower, but again comparisons are limited by differences in assay parameters. Previous determinations were carried out using an endpoint gel shift assay, whereas we used a real-time kinetic approach. Regardless, these results suggest that the BoTest ${ }^{\mathrm{TM}} \mathrm{A} / \mathrm{E}$ reporter binds to BoNTs/A and $\mathrm{E}$ with high affinity and is efficiently cleaved by the respective proteases.

The $K_{\mathrm{M}}$ values for the cleavage of BoTest ${ }^{\mathrm{TM}} \mathrm{B} / \mathrm{D} / \mathrm{F} / \mathrm{G}$ by BoNTs/B, $\mathrm{D}$, and $\mathrm{F}$ range from 8.5 to $17.5 \mu \mathrm{M}$. Similar values were reported for cleavage of recombinant synaptobrevin (residues 1-96 or 197 ) by the three serotypes using gel shift assays $[47,48]$. The $K_{\mathrm{M}}$ values for cleavage of BoTest ${ }^{\mathrm{TM}} \mathrm{B} / \mathrm{D} / \mathrm{F} / \mathrm{G}$ are more than 10 times higher than the $K_{\mathrm{M}}$ values for cleavage of BoTest ${ }^{\mathrm{TM}} \mathrm{A} / \mathrm{E}$ by BoNTs/ $\mathrm{A}$ and $\mathrm{E}$. In addition, the catalytic efficiencies $\left(k_{\text {cat }} / K_{\mathrm{M}}\right)$ for BoNTs/ $\mathrm{B}, \mathrm{D}$, and $\mathrm{F}$ are one to three orders of magnitude lower than those for BoNTs/A and E. Overall, the cleavage of BoTest ${ }^{\mathrm{TM}} \mathrm{B} / \mathrm{D} / \mathrm{F} / \mathrm{G}$ reporter occurs with lower affinity and efficiency than the cleavage of BoTest $^{\mathrm{TM}} \mathrm{A} / \mathrm{E}$ reporter.

\section{Comparisons with SNAPtide}

BoNT antagonist development, and thus the development of therapies, is hampered by the lack of high-throughput assays that can replicate native BoNT-substrate interactions and can be used in a cost-effective manner. SNAPtide (List Biological Laboratories) is a fluorogenic reporter for the detection of BoNT/A proteolytic activity that has long been used to characterize BoNT-drug interactions or BoNT enzymatic activity [49-52]. This reporter consists of a short peptide sequence with an internal donor/acceptor FRET pair, with the acceptor acting as a quencher. Cleavage of the peptide results in an increase of fluorescence emission due to loss of donor quenching. The relatively short peptide sequence used in SNAPtide, however, results in a substrate that must be used at high concentrations due to its low affinity for BoNT.

To determine whether BoTest ${ }^{\mathrm{TM}}$ provides a better alternative for high-throughput applications, we compared SNAPtide and BoTest ${ }^{\mathrm{TM}}$ for their ability to detect BoNT/A proteolytic activity with statistical significance (Fig. 7). BoTest ${ }^{\mathrm{TM}}$, as expected, could detect picomolar concentrations of BoNT/A, whereas SNAPtide provided little detection below $1 \mathrm{nM}$ BoNT (Fig. 7A). We next analyzed the data for statistical significance using $Z^{\prime}$ factor calculations to assess assay dynamic range and data variation, with a $Z$ ' factor value of more than 0.5 signifying an acceptable assay for high-throughput applications [53]. The BoTest ${ }^{\mathrm{TM}}$ assay gave $Z$ ' factor values of more than 0.5 at BoNT/A concentrations of $10 \mathrm{pM}$ or above, whereas the SNAPtide assay gave acceptable values at BoNT/A concentrations of $3 \mathrm{nM}$ or above (Fig. 7B). The 300-fold difference in BoNT/A concentrations required to meet a common acceptance criterion for HTS between BoTest ${ }^{\mathrm{TM}}$ and SNAPtide has implications for the cost of carrying out large-scale drug screening projects. The commercial BoNT/A cost for a single 96-well plate is approximately US $\$ 0.07$ at $10 \mathrm{pM}$ and $\$ 21.62$ at $3 \mathrm{nM}$; thus, for SNAPtide the cost of the en- zyme (BoNT) will be one of the major considerations for HTS applications, whereas for BoTest ${ }^{\mathrm{TM}}$ the cost of enzyme will be of minimal consideration.

\section{Discussion}

BoTest ${ }^{\mathrm{TM}}$ reporters have several advantages over existing BoNT detection platforms. The reporters do not require animal sacrifice, offer real-time capabilities, and do not require sophisticated equipment or extensive training to perform. They also offer a single methodology for the detection of six of seven serotypes of BoNT, the only technology to do so outside of MS- and high-performance liquid chromatography (HPLC)-based platforms. Efforts to adapt the reporters for BoNT/C, the only serotype not detected by these reporters, are ongoing. Finally, these reporters are high-affinity BoNT substrates that offer picomolar to femtomolar sensitivity depending on the serotypes of interest.

BoNT antagonist development has been largely limited to studies of small sets of compounds or peptides chosen through rational design, computer-assisted, or other methods [54-59]. Although these studies have provided a considerable amount of information about BoNT catalytic mechanism and substrate requirements, few of the small molecule inhibitors that have emerged from these studies have sufficient potency to be effective BoNT therapeutics. Large-scale HTS efforts, the basis for most modern drug discovery, are absent from BoNT antagonist development programs; thus, the potential of the many small molecule and natural product libraries found at public and private laboratories has been largely untapped. Successful development of BoNT therapeutics could be accelerated greatly if screens of more than 10,000 compounds were more commonplace and the information from those screens was shared among biodefense laboratories.

A partial explanation for the lack of large-scale HTS efforts likely resides in the lack of assays suitable for HTS. A variety of novel BoNT detection platforms with varying sensitivities, serotype specificities, and mechanisms have been described [23]. However, few platforms are suitable for HTS because many require multiple detection steps to complete, lack sensitivity, or require equipment that is too expensive or ill-suited for HTS applications. For example, many fluorescent-based methods for the detection of BoNT/A that rely on synthetic peptides often use short substrates with low affinity and low sensitivity $[27,28,52]$. The poor sensitivity requires that large quantities of BoNT be used to generate a suitable signal, raising the cost of HTS to unacceptable levels (Fig. 7). Furthermore, the low-affinity substrates limit the number and types of inhibitors obtained from the screens. Ideally, HTS is carried out with a substrate concentration at or near the $K_{\mathrm{M}}$ value of the enzyme to be screened to increase inhibitor mechanism diversity [60]. Many fluorescence-based reporters have reported $K_{\mathrm{M}}$ values of $100 \mu \mathrm{M}$ or above; thus, high concentrations of reporter must be used, further increasing the costs of HTS [28,52]. Short substrates also limit screens to active site inhibitors while ignoring the potential of exploiting the strong binding interactions or exosites that occur between BoNT and longer substrates, such as the BoTest ${ }^{\mathrm{TM}}$ reporters, that are remote from the active site $[6,7,44,47,48,61-63]$. 
A

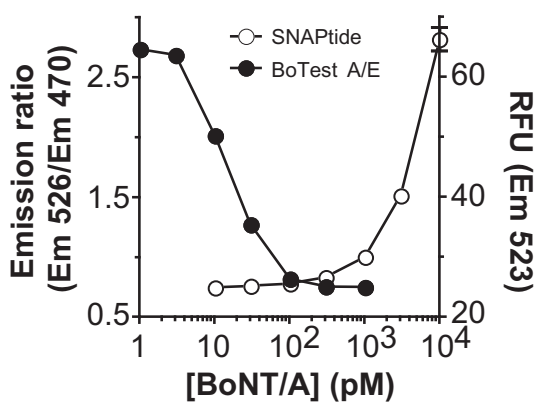

B

\begin{tabular}{|c|c|c|c|}
\hline \multirow[b]{2}{*}{ [BoNT] (pM) } & \multicolumn{2}{|c|}{$Z^{\prime}(B o N T / A)$} & \multirow{2}{*}{$\begin{array}{l}\text { BoNT cost } \\
\text { per plate }(\$)\end{array}$} \\
\hline & BoTest $\mathrm{A} / \mathrm{E}$ & SNAPtide & \\
\hline 1 & -9.18 & ND & 0.01 \\
\hline 3 & -6.44 & ND & 0.02 \\
\hline 10 & 0.64 & -9.51 & 0.07 \\
\hline 30 & 0.83 & -19.4 & 0.22 \\
\hline 100 & 0.91 & -3.29 & 0.72 \\
\hline 300 & 0.92 & -0.57 & 2.16 \\
\hline 1000 & 0.92 & 0.23 & 7.21 \\
\hline 3000 & ND & 0.79 & 21.62 \\
\hline 10000 & ND & 0.83 & 72.07 \\
\hline
\end{tabular}

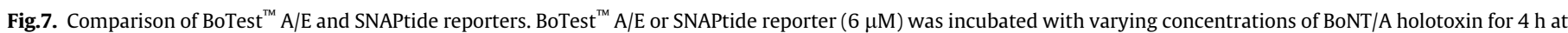

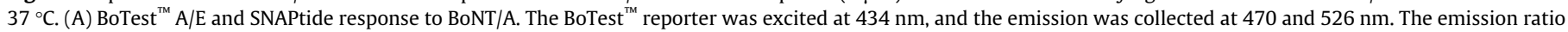

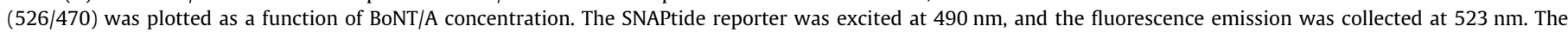

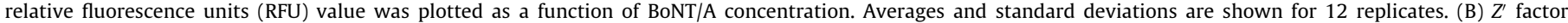

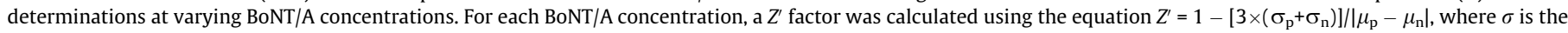

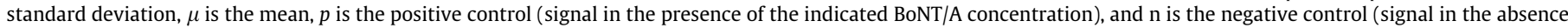
of BoNT/A). BoNT cost per plate was based on a 96-well microtiter plate at $100 \mu \mathrm{l}$ per well and the retail cost of a commercially available preparation of BoNT/A.

The detection methods described here meet the requirements for HTS. First, the BoTest ${ }^{\mathrm{TM}}$ assays require only a single mix and read step. Second, the BoTest ${ }^{\mathrm{TM}}$ assays are sensitive and meet common criteria for acceptable HTS assay performance (Table 1 and Fig. 7). Third, the reporters used in the assays react with BoNT with low or sub-micromolar $K_{\mathrm{M}}$ values, allowing cost-effective drug testing using substrate concentrations at or near the $K_{\mathrm{M}}$ value of the reaction. Future studies done by our group or by laboratories using the BoTest ${ }^{\mathrm{TM}}$ assays will fully realize the potential of the reporters for BoNT inhibitor discovery.

A second area of advancements represented by these methods is the ability to accurately quantify BoNT proteolytic activity from six of seven serotypes with high sensitivity, relative ease, and application-specific adaptability. The assays can be used in an endpoint fashion with femtomolar to picomolar sensitivity (Figs. 3 and 4 ), or they can be used to quantify enzyme-specific activity with CVs of approximately $10 \%$ (Fig. 6). Ongoing work also shows that the assays can be used in combination with immunological methods to measure the activity in complex matrices such as serum, carrot juice, and whole blood (data not shown). With further adaptation, the BoTest ${ }^{\mathrm{TM}}$ assays should be applicable to a wide range of environmental, biodefense, drug manufacturing, and pharmaceutical needs where high sensitivity detection of BoNT activity is required.

\section{Acknowledgments}

The authors thank E.R. Chapman, M. Dong, W. Checovich, and D. Atapattu for valuable discussions and advice. This research was supported in part by a Department of Defense award (07-20045). T.M.P. is supported in part by the US Geological Survey (USGS)-National Wildlife Health Center and the National Park Service. The views, opinions, and findings presented here are those of the authors and should not be construed as official Department of the Army positions, policies, or decisions unless designated by other documentation. Citation of trade names in this article does not constitute official Department of the Army endorsement or approval of the use of such commercial items.

\section{Appendix A. Supplementary data}

Supplementary data associated with this article can be found, in the online version, at doi:10.1016/j.ab.2011.01.002.

\section{References}

[1] G. Schiavo, F. Benfenati, B. Poulain, O. Rossetto, P. Polverino de Laureto, B.R DasGupta, C. Montecucco, Tetanus and botulinum-B neurotoxins block neurotransmitter release by proteolytic cleavage of synaptobrevin, Nature 359 (1992) 832-835.

[2] J. Blasi, E.R. Chapman, E. Link, T. Binz, S. Yamasaki, P. De Camilli, T.C. Sudhof, H. Niemann, R. Jahn, Botulinum neurotoxin A selectively cleaves the synaptic protein SNAP-25, Nature 365 (1993) 160-163.

[3] J. Blasi, E.R. Chapman, S. Yamasaki, T. Binz, H. Niemann, R. Jahn, Botulinum neurotoxin C1 blocks neurotransmitter release by means of cleaving HPC-1/ syntaxin, EMBO J. 12 (1993) 4821-4828.

[4] G. Schiavo, O. Rossetto, S. Catsicas, P. Polverino de Laureto, B.R. DasGupta, F. Benfenati, C. Montecucco, Identification of the nerve terminal targets of botulinum neurotoxin serotypes A, D, and E, J. Biol. Chem. 268 (1993) 2378423787.

[5] G. Schiavo, C.C. Shone, O. Rossetto, F.C. Alexander, C. Montecucco, Botulinum neurotoxin serotype $F$ is a zinc endopeptidase specific for VAMP/ synaptobrevin, J. Biol. Chem. 268 (1993) 11516-11519.

[6] O. Rossetto, G. Schiavo, C. Montecucco, B. Poulain, F. Deloye, L. Lozzi, C.C. Shone, SNARE motif and neurotoxins, Nature 372 (1994) 415-416.

[7] S. Yamasaki, A. Baumeister, T. Binz, J. Blasi, E. Link, F. Cornille, B. Roques, E.M. Fykse, T.C. Sudhof, R. Jahn, et al., Cleavage of members of the synaptobrevin/ VAMP family by types D and F botulinal neurotoxins and tetanus toxin, J. Biol. Chem. 269 (1994) 12764-12772.

[8] G. Schiavo, C. Malizio, W.S. Trimble, P. Polverino de Laureto, G. Milan, H. Sugiyama, E.A. Johnson, C. Montecucco, Botulinum G neurotoxin cleaves VAMP/synaptobrevin at a single Ala-Ala peptide bond, J. Biol. Chem. 269 (1994) 20213-20216.

[9] J. Sobel, Botulism, Clin. Infect. Dis. 41 (2005) 1167-1173.

[10] R.A. Greenfield, B.R. Brown, J.B. Hutchins, J.J. Iandolo, R. Jackson, L.N. Slater, M.S. Bronze, Microbiological, biological, and chemical weapons of warfare and terrorism, Am. J. Med. Sci. 323 (2002) 326-340.

[11] S.S. Arnon, R. Schechter, T.V. Inglesby, D.A. Henderson, J.G. Bartlett, M.S Ascher, E. Eitzen, A.D. Fine, J. Hauer, M. Layton, S. Lillibridge, M.T. Osterholm, T. O'Toole, G. Parker, T.M. Perl, P.K. Russell, D.L. Swerdlow, K. Tonat, Botulinum toxin as a biological weapon: medical and public health management, JAMA 285 (2001) 1059-1070.

[12] L.M. Wein, Y. Liu, Analyzing a bioterror attack on the food supply: the case of botulinum toxin in milk, Proc. Natl. Acad. Sci. USA 102 (2005) 9984-9989.

[13] P. Bossi, D. Garin, A. Guihot, F. Gay, J.M. Crance, T. Debord, B. Autran, F. Bricaire, Bioterrorism: management of major biological agents, Cell. Mol. Life Sci. 63 (2006) 2196-2212.

[14] R. Benecke, D. Dressler, Botulinum toxin treatment of axial and cervical dystonia, Disabil. Rehabil. 29 (2007) 1769-1777.

[15] D. Sinha, K. Karri, A.S. Arunkalaivanan, Applications of botulinum toxin in urogynaecology, Eur. J. Obstet. Gynecol. Reprod. Biol. 133 (2007) 4-11.

[16] S.T. Mahajan, L. Brubaker, Botulinum toxin: from life-threatening disease to novel medical therapy, Am. J. Obstet. Gynecol. 196 (2007) 7-15.

[17] R. Dmochowski, P.K. Sand, Botulinum toxin A in the overactive bladder: current status and future directions, BJU Intl. 99 (2007) 247-262.

[18] D.A. Kautter, H.M. Solomon, Collaborative study of a method for the detection of Clostridium botulinum and its toxins in foods, J. Assoc. Anal. Chem. 60 (1976) 541-545.

[19] AOAC International, Clostridium botulinum and its toxins in foods (method 977.26, section 17.7.01), in: W. Horwitz (Ed.), Official Methods of Analysis of AOAC International, 17th ed., Gaithersburg, MD, 2001. 
[20] E.J. Schantz, D.A. Kautter, Microbiological methods: standardized assay for Clostridium botulinum toxins, J. AOAC 61 (1978) 96-99.

[21] S. Notermans, J. Nagel, Assays for botulinum and tetanus toxins, in: L.L. Simpson (Ed.), Botulinum Neurotoxin and Tetanus Toxin, Academic Press, New York, 1989, pp. 319-331.

[22] J.L. Ferreira, Comparison of amplified ELISA and mouse bioassay procedures for determination of botulinal toxins A, B, E, and F, J. AOAC Intl. 84 (2001) 85-88

[23] S. Cai, B.R. Singh, S. Sharma, Botulism diagnostics: from clinical symptoms to in vitro assays, Crit. Rev. Microbiol. 33 (2007) 109-125.

[24] A.E. Boyer, H. Moura, A.R. Woolfitt, S.R. Kalb, L.G. McWilliams, A. Pavlopoulos, J.G. Schmidt, D.L. Ashley, J.R. Barr, From the mouse to the mass spectrometer: detection and differentiation of the endoproteinase activities of botulinum neurotoxins A-G by mass spectrometry, Anal. Chem. 77 (2005) 3916-3924.

[25] S.R. Kalb, H. Moura, A.E. Boyer, L.G. McWilliams, J.L. Pirkle, J.R. Barr, The use of Endopep-MS for the detection of botulinum toxins A, B, E, and F in serum and stool samples, Anal. Biochem. 351 (2006) 84-92.

[26] C. Anne, F. Cornille, C. Lenoir, B.P. Roques, High-throughput fluorogenic assay for determination of botulinum type B neurotoxin protease activity, Anal. Biochem. 291 (2001) 253-261.

[27] J.J. Schmidt, R.G. Stafford, C.B. Millard, High-throughput assays for botulinum neurotoxin proteolytic activity: serotypes A, B, D, and F, Anal. Biochem. 296 (2001) 130-137.

[28] J.J. Schmidt, R.G. Stafford, Fluorigenic substrates for the protease activities of botulinum neurotoxins, serotypes A, B, and F, Appl. Environ. Microbiol. 69 (2003) 297-303.

[29] M. Pires-Alves, M. Ho, K.K. Aberle, K.D. Janda, B.A. Wilson, Tandem fluorescent proteins as enhanced FRET-based substrates for botulinum neurotoxin activity, Toxicon 53 (2009) 392-399.

[30] N.T. Salzameda, J.T. Barbieri, K.D. Janda, Synthetic substrate for application in both high and low throughput assays for botulinum neurotoxin B protease inhibitors, Bioorg. Med. Chem. Lett. 19 (2009) 5848-5850.

[31] H. Poras, T. Ouimet, S.V. Orng, M.C. Fournie-Zaluski, M.R. Popoff, B.P. Roques, Detection and quantification of botulinum neurotoxin type A by a novel rapid in vitro fluorimetric assay, Appl. Environ. Microbiol. 75 (2009) 4382-4390.

[32] M. Dong, W.H. Tepp, E.A. Johnson, E.R. Chapman, Using fluorescent sensors to detect botulinum neurotoxin activity in vitro and in living cells, Proc. Natl. Acad. Sci. USA 101 (2004) 14701-14706.

[33] T.G. Schmidt, A. Skerra, The Strep-Tag system for one-step purification and high-affinity detection or capturing of proteins, Nat. Protoc. 2 (2007) 1528 1535.

[34] T. Nagai, K. Ibata, E.S. Park, M. Kubota, K. Mikoshiba, A. Miyawaki, A variant of yellow fluorescent protein with fast and efficient maturation for cell-biological applications, Nat. Biotechnol. 20 (2002) 87-90.

[35] D.A. Zacharias, J.D. Violin, A.C. Newton, R.Y. Tsien, Partitioning of lipidmodified monomeric GFPs into membrane microdomains of live cells, Science 296 (2002) 913-916.

[36] J.L. Vinkenborg, T.H. Evers, S.W. Reulen, E.W. Meijer, M. Merkx, Enhanced sensitivity of FRET-based protease sensors by redesign of the GFP dimerization interface, Chem. BioChem. 8 (2007) 1119-1121.

[37] J.R. Lakowicz, Principles of Fluorescence Spectroscopy, Kluwer Academic Plenum, New York, 1999.

[38] T.B. Helting, S. Parschat, H. Engelhardt, Structure of tetanus toxin: demonstration and separation of a specific enzyme converting intracellular tetanus toxin to the extracellular form, J. Biol. Chem. 254 (1979) 10728-10733.

[39] U. Weller, M.E. Dauzenroth, D. Meyer zu Heringdorf, E. Habermann, Chains and fragments of tetanus toxin: separation, reassociation, and pharmacological properties, Eur. J. Biochem. 182 (1989) 649-656.

[40] G. Schiavo, M. Matteoli, C. Montecucco, Neurotoxins affecting neuroexocytosis, Physiol. Rev. 80 (2000) 717-766.

[41] D. Sesardic, T. Leung, R. Gaines Das, Role for standards in assays of botulinum toxins: international collaborative study of three preparations of botulinum type A toxin, Biologicals 31 (2003) 265-276.

[42] P. Washbourne, R. Pellizzari, G. Baldini, M.C. Wilson, C. Montecucco, Botulinum neurotoxin types A and E require the SNARE motif in SNAP-25 for proteolysis, FEBS Lett. 418 (1997) $1-5$.

[43] R. Agarwal, T. Binz, S. Swaminathan, Analysis of active site residues of botulinum neurotoxin $\mathrm{E}$ by mutational, functional, and structural studies: Glu335Gln is an apoenzyme, Biochemistry 44 (2005) 8291-8302.

[44] S. Chen, J.T. Barbieri, Unique substrate recognition by botulinum neurotoxin serotypes A and E, J. Biol. Chem. 281 (2006) 10906-10911.
[45] T. Binz, S. Bade, A. Rummel, A. Kollewe, J. Alves, $\operatorname{Arg}_{362}$ and $\operatorname{Tyr}_{365}$ of the botulinum neurotoxin type A light chain are involved in transition state stabilization, Biochemistry 41 (2002) 1717-1723.

[46] L. Li, T. Binz, H. Niemann, B.R. Singh, Probing the mechanistic role of glutamate residue in the zinc-binding motif of type A botulinum neurotoxin light chain, Biochemistry 39 (2000) 2399-2405.

[47] S. Sikorra, T. Henke, T. Galli, T. Binz, Substrate recognition mechanism of VAMP/synaptobrevin-cleaving clostridial neurotoxins, J. Biol. Chem. 283 (2008) 21145-21152.

[48] S. Chen, C. Hall, J.T. Barbieri, Substrate recognition of VAMP-2 by botulinum neurotoxin B and tetanus neurotoxin, J. Biol. Chem. 283 (2008) 2115321159.

[49] M.R. Baldwin, M. Bradshaw, E.A. Johnson, J.T. Barbieri, The C-terminus of botulinum neurotoxin type A light chain contributes to solubility, catalysis, and stability, Protein Expr. Purif. 37 (2004) 187-195.

[50] J.S. Henkel, M. Jacobson, W. Tepp, C. Pier, E.A. Johnson, J.T. Barbieri, Catalytic properties of botulinum neurotoxin subtypes A3 and A4, Biochemistry 48 (2009) 2522-2528.

[51] L.M. Eubanks, M.S. Hixon, W. Jin, S. Hong C.M. Clancy, W.H. Tepp, M.R Baldwin, C.J. Malizio, M.C. Goodnough, J.T. Barbieri, E.A. Johnson, D.L. Boger, T.J. Dickerson, K.D. Janda, An in vitro and in vivo disconnect uncovered through high-throughput identification of botulinum neurotoxin A antagonists, Proc. Natl. Acad. Sci. USA 104 (2007) 2602-2607.

[52] G.E. Boldt, J.P. Kennedy, M.S. Hixon, L.A. McAllister, J.T. Barbieri, S. Tzipori, K.D. Janda, Synthesis, characterization, and development of a high-throughput methodology for the discovery of botulinum neurotoxin A inhibitors, J. Comb. Chem. 8 (2006) 513-521.

[53] J.H. Zhang, T.D. Chung, K.R. Oldenburg, A simple statistical parameter for use in evaluation and validation of high throughput screening assays, J. Biomol. Screen. 4 (1999) 67-73.

[54] J.C. Burnett, E.A. Henchal, A.L. Schmaljohn, S. Bavari, The evolving field of biodefense: therapeutic developments and diagnostics, Nat. Rev. Drug Discov. 4 (2005) 281-297.

[55] J.C. Burnett, C. Wang, J.E. Nuss, T.L. Nguyen, A.R. Hermone, J.J. Schmidt, R. Gussio, P. Wipf, S. Bavari, Pharmacophore-guided lead optimization: the rational design of a non-zinc coordinating, sub-micromolar inhibitor of the botulinum neurotoxin serotype A metalloprotease, Bioorg. Med. Chem. Lett. 19 (2009) 5811-5813.

[56] J.C. Burnett, G. Ruthel, C.M. Stegmann, R.G. Panchal, T.L. Nguyen, A.R. Hermone, R.G. Stafford, D.J. Lane, T.A. Kenny, C.F. McGrath, P. Wipf, A.M. Stahl, J.J. Schmidt, R. Gussio, A.T. Brunger, S. Bavari, Inhibition of metalloprotease botulinum serotype A from a pseudo-peptide binding mode to a small molecule that is active in primary neurons, J. Biol. Chem. 282 (2007) 50045014.

[57] A.R. Hermone, J.C. Burnett, J.E. Nuss, L.E. Tressler, T.L. Nguyen, B.A. Solaja, J.L. Vennerstrom, J.J. Schmidt, P. Wipf, S. Bavari, R. Gussio, Three-dimensional database mining identifies a unique chemotype that unites structurally diverse botulinum neurotoxin serotype $\mathrm{A}$ inhibitors in a three-zone pharmacophore, Chem. Med. Chem. 3 (2008) 1905-1912.

[58] C. Anne, S. Turcaud, J. Quancard, F. Teffo, H. Meudal, M.C. Fournie-Zaluski, B.P. Roques, Development of potent inhibitors of botulinum neurotoxin type B, J. Med. Chem. 46 (2003) 4648-4656.

[59] V. Roxas-Duncan, I. Enyedy, V.A. Montgomery, V.S. Eccard, M.A. Carrington, H. Lai, N. Gul, D.C. Yang, L.A. Smith, Identification and biochemical characterization of small-molecule inhibitors of Clostridium botulinum neurotoxin serotype A, Antimicrob. Agents Chemother. 53 (2009) 34783486.

[60] R.A. Copeland, Evaluation of Enzyme Inhibitors in Drug Discovery, John Wiley, Hoboken, NJ, 2005.

[61] M.A. Breidenbach, A.T. Brunger, Substrate recognition strategy for botulinum neurotoxin serotype A, Nature 432 (2004) 925-929.

[62] R. Pellizzari, O. Rossetto, L. Lozzi, S. Giovedi, E. Johnson, C.C. Shone, C. Montecucco, Structural determinants of the specificity for synaptic vesicleassociated membrane protein/synaptobrevin of tetanus and botulinum type B and G neurotoxins, J. Biol. Chem. 271 (1996) 20353-20358.

[63] V.V. Vaidyanathan, K. Yoshino, M. Jahnz, C. Dorries, S. Bade, S. Nauenburg, H. Niemann, T. Binz, Proteolysis of SNAP-25 isoforms by botulinum neurotoxin types $\mathrm{A}, \mathrm{C}$, and $\mathrm{E}$ : domains and amino acid residues controlling the formation of enzyme-substrate complexes and cleavage, J. Neurochem. 72 (1999) 327 337. 